\title{
Paulina Chiziane: Uma Contadora de Histórias no Ritmo da (Contra-)Dança Jorge Valentim (UFSCar)
}

\section{RESUMO}

O presente trabalho propõe um caminho de leitura de Niketche, mais recente romance da escritora moçambicana Paulina Chiziane, apontando os recursos musicais como elementos participantes de uma prática oralizante. No ritmo da dança, a trajetória das personagens são entretecidas, bem como a própria construção do texto em si. Dentro de uma visão de mundo feminina, cria-se um universo marcado pela musicalidade e redimensão da língua portuguesa e pela construção musical do texto ficcional. Palavras-chave: Paulina Chiziane, Literatura e musicalidade, romance moçambicano.

\section{UMA CONTADORA/CANTADORA DE HISTÓRIAS}

\begin{abstract}
Gosto de dizer que a minha literatura é isso: contar histórias. Aquilo que outras mulheres fazem dançando e cantando, eu faço escrevendo, como as velhas que através da via oral continuam a contar histórias à volta da fogueira. Eu apenas trago a escrita, de resto não sou diferente das mulheres da minha terra, das mulheres do campo.
\end{abstract}

(Paulina Chiziane, Entrevista ao Maderazinco)

É praticamente unânime a constatação da crítica literária, direcionada aos estudos africanos, de que a oralidade é uma marca preponderante nas produções culturais e artísticas dos mais diversos países do continente. Tal aspecto, portanto, pode ser nitidamente observado em diversas obras de autores africanos, nas mais diversas épocas e das mais distintas nacionalidades, abrangendo não só a dimensão literária escrita, mas também a artística, que envolve a dança, a música vocal e instrumental e a pantomima. Tomando como ponto referencial para o estudo deste recurso, o mais recente romance da escritora moçambicana Paulina Chiziane, publicado no Brasil sob a chancela da Companhia das Letras, Niketche1, encontramos para além da convivência da prática oralizante no texto literário, a presença de vários elementos pertinentes à cultura autóctone, a partir do próprio título, nome de uma dança ritual de iniciação sexual feminina, de teor altamente sensual e erótico, executada pelas raparigas quando da realização dos ritos.

Originária da Zambézia e de Nampula, região norte de Moçambique predominantemente macua, niketche "é a dança do sol e da lua, dança do vento e da chuva, dança da criação. Uma dança que mexe, que aquece. Que imobiliza o corpo e faz a alma voar" (N, p. 160). Executada ao "som ritmado dos batuques" (Ibidem), niketche constitui uma espécie de expressão autêntica da feminilidade moçambicana, numa parte do país onde o mundo familiar é essencialmente matriarcal. A partir daí, estabelece-se um contraponto - ou melhor dizendo, uma contradança? - com a tradição da região sul, dominada pelo patriarcalismo, espaço de origem da protagonista Rami. 
No entanto, o que poderia ser compreendido como uma mera contraposição de valores, a autora estabelece um outro ritmo cultural na realização da dança. Isto porque as tendências familiares em Moçambique tiveram os seus alicerces abalados devido a, pelo menos, duas influências capitais: a do islamismo, no norte, fazendo com que esta região de Moçambique ganhasse uma configuração patriarcal e poligâmica, e a do catolicismo, no sul, provocando uma contestação desta prática. Assim, todos os valores tradicionais são colocados em xeque a partir da introdução de uma nova espécie de religião, mudando por completo os hábitos considerados comuns e fazendo-os conviverem com outras práticas, assimiladas pelo elemento colonizado. Segundo Fátima Nordine Mussá, "os nativos incorporaram novos valores e práticas advindas da sua nova religião, associando a esta suas crenças e cultos” (MUSSÁ, 2001, p. 131).

Atenta observadora das intensas tensões culturais de seu país, a própria escritora também vivenciou uma delas, a das diferenças plurilingüísticas. Natural de Manjacaze, na província sulista de Gaza, Paulina estudou em Maputo, juntando à sua língua natal, o chope, o ronga e o português. Através desta confluência, a autora conseguiu, segundo Inocência Mata, "harmonizar diferenças e construir a utopia da harmoniosa convivência entre valores tradicionais e essoutros advindos da tradição européia" (MATA, 2000, p. 135), num universo marcado pela sua prática dinâmica como contadora e cantadora de histórias.

\section{NO RITMO FEMININO, O DESCOMPASSO EM CONTRA-DANÇA COM O MUNDO MASCULINO}

Em todas as guerras do mundo nunca houve arma mais fulminante que a mulher, mas é aos homens que cabem as honras de generais.

(Paulina Chiziane. Ventos do Apocalipse)

É com um olhar feminino agudo e sensível frente às tradições nacionais que Paulina Chiziane traz à tona a trama familiar de Rami, mulher do sul, protagonistanarradora que se descobre traída e trocada por outras quatro mulheres, diante da prática poligâmica de seu marido Tony. Cada uma delas, de uma parte diferente do país, na visão da narradora, metaforiza a possibilidade de uma união nacional, cujo eixo centralizador seria a figura do homem das cinco casas: "Mas nós já somos uma variação, em línguas, em hábitos, em culturas. Somos uma amostra de norte a sul, o país inteiro nas mãos de um só homem. Em matéria de amor, o Tony simboliza a unidade nacional" (N, p. 161).

Consciente de que "as culturas são fronteiras invisíveis construindo a fortaleza do mundo" (N, p. 39), Rami parte numa viagem de reconhecimento das outras mulheres de seu marido. É com surpresa que constata no lar de cada uma de suas rivais algo que, na sua relação conjugal, sempre lhe fora proibido, como o caso do retrato na parede com o marido, numa exibição pública do amor, na casa de Julieta, a segunda mulher. Uma após outra, os encontros se dão de forma violenta, as mulheres lutam com unhas e dentes, como as fêmeas em defesa de seu macho, a ponto mesmo de, no primeiro encontro com Luísa, a terceira esposa, as duas terminarem na cadeia. Só então, Rami tem condições de perceber que, na verdade, a sua solidão é também compartilhada por todas elas. Olhar a casa vazia, sentir a ausência do marido desejado e experimentar a solidão são privilégios coletivos desta comunidade poligâmica em que as certezas absolutas se tornam altamente relativas: "Ter é uma das muitas ilusões da existência, porque o ser humano nasce e morre de mãos vazias. Tudo o que julgamos ter, é-nos emprestado pela vida durante pouco tempo" (N, p. 25).

Independente de suas origens - macuas, macondes ou senas - todas elas acabam por se tornar vítimas. Primeiramente das instituições colonizadoras, sobretudo igreja e o 
sistema que "gritaram heresias" contra a prática dos ritos tradicionais, tentando "destruir um saber que nem eles tinham" ( $N$, p. 44). Abrindo mão de sua cultura autóctone em favor de uma outra que não lhe diz respeito, o colonizado "destrói o seu, assimila o alheio, sem enxergar o próprio umbigo" ( $N$, p. 45), esquecendo inclusive que "os ritos de iniciação são uma instituição mais importante que todas as outras instituições formais juntas, cujos segredos não se divulgam nunca" (Ibidem). Ou então, a própria cultura masculina a que estão subjugadas e submetidas, que tolhe, reprime e impede a atuação efetiva do sujeito feminino, posto que, segundo a própria autora, em entrevista ao JL, "é dentro da família que se geram todos os pequenos e grandes mecanismos que reprimem a mulher" (CHIZIANE, 2001, p. 4).

Como, então, driblar um meio social colonialista e repressor ? Talvez, uma das formas encontradas pela autora, também inserida no mesmo contexto cultural apontado na ficção, seria a de reavivar as formas tradicionais apagadas pelo discurso colonizador e esquecidas pelo discurso masculino, através do ritmo sedutor e erótico da música e da dança, dois elementos fundamentais para a manutenção da cultura autóctone. Assim fazendo, a autora reitera a condição da música em Moçambique, que, segundo John Marney, "foi e é utilizada para reforçar a identidade cultural" (MARNEY, 1980, p. 16). Desta forma, reunindo as seis personagens sob a liderança de Rami, a primeira esposa, a rainha, a responsável pela ordem desta união poligâmica, a música de Niketche vai sendo gradualmente composta, servindo como uma espécie de trilha sonora para a "encenação quotidiana do feminino" (MATA, 2000, p. 136), para a representação de uma história da sexualidade no ritmo do compasso feminino.

É também no ritmo do canto e da dança que o fio narrativo de Niketche vai sendo tecido. No lugar de escrever romances, a autora cede às suas tradições originais e recorre à escrita, da mesma forma como outras mulheres recorrem à dança e ao canto. Equivaleria, portanto, dizer que tais recursos musicais expressivos também são utilizados por Paulina Chiziane no seu exercício ficcional. Neste sentido, a narradoraprotagonista parece exprimir um desejo muito próximo desta prática cantante:

Titubeio uma canção antiga daquelas que arrastam as lágrimas à superfície. Nessa coisa de cantar, tenho as minhas raízes. Sou de um povo cantador. Nesta terra canta-se na alegria e na dor. A vida é um grande canto. Canto e choro. Delicio-me com as lágrimas que correm com sabor a sal, com o maior prazer do mundo" ( $N$ p. 15).

Como, então, não perceber neste canto titubeado e plangente a veia lírica da escrita pauliniana ? Como não encontrar, aqui, uma consonância com aquela idéia de que "a prosa só é verdadeiramente prosa bonita quando se aproxima da poesia. Prosa sem aquela musicalidade poética parece um pão mal amassado, sem gosto" (CHABAL, 1994, p. 301) ? Certamente, evitando e negando a prática literária sem gosto, Paulina Chiziane baseia sua escrita na dinâmica da oralidade e, com ela, traz o canto e também a dança, expressões artísticas importantes nas sociedades africanas, unindo-os todos na e através da palavra e redimensionando no espaço da ficção uma manifestação singular de uma subjetividade essencialmente feminina. Assim, práticas musicais se encontram integradas no espaço oralizante da palavra, reiterando a idéia de que "as músicas tradicionais africanas se desenvolvem num contexto de oralidade pura" (BRANDILY, 1997, p. 22). Se "a vida é um grande canto", como nos faz crer a autora, nela também há espaço para a dança na pantomima da vida:

Paro de soluçar e fico em silêncio para escutar a canção mágica desta dança. É o meu silêncio que escuto. E o meu silêncio dança, fazendo dançar o meu ciúme, a minha solidão, a minha mágoa. A minha cabeça também entra na dança, sinto vertigens. (...) Dançar a derrota do meu adversário. Dançar na festa do meu aniversário. Dançar sobre a coragem do inimigo. Dançar no funeral do ente querido. Dançar à volta da fogueira na véspera do 
grande combate. Dançar é orar. Eu também quero dançar. A vida é uma grande dança" (N, p. 16).

É, portanto, com os passos da dança que a trajetória de Rami vai sendo contada. De mulher traída e abandonada passa a rainha de uma sociedade poligâmica, líder do clube das esposas de Tony. $\mathrm{Na}$ construção de sua trajetória não faltam etapas que evidenciam a visão feminina de Paulina Chiziane diante da realidade social moçambicana. Tal forma de olhar o universo feminino pontua os passos determinantes da dança dentro do romance. Cada um deles representaria uma espécie de aprendizado.

No aprendizado tardio das mais antigas tradições africanas, esquecidas diante de uma educação colonizadora "na igreja, com os padres e as freiras" ( $N$, p. 35), com uma conselheira de amor, Rami aprende o tratamento da pele com musiro, nos ritos de adolescência, e com mel, nos ritos de noivado, e lembra-se de que "ninguém nasce mulher, torna-se mulher" (Ibidem). E, como mulher moçambicana, aprende os tabus, como o do ovo, "que não pode ser comido por mulheres, para não terem filhos carecas e não se comportarem como galinhas poedeiras na hora do parto" (Ibidem, p. 36); os mitos, como os que "aproximam as meninas do trabalho doméstico e afastam os homens do pilão, do fogo e da cozinha para não apanharem doenças sexuais, como esterilidade e impotência" (Ibid.); e também os hábitos alimentares que "obrigam as mulheres a servir aos maridos os melhores nacos de carne, ficando para elas os ossos, as patas, as asas e o pescoço" (Ibid.). Com a mãe, mulher mais velha e experiente, Rami compreende a dimensão e o peso das práticas tradicionais que permitem ao homem castigar severamente a mulher desobediente dos ritos, como o caso de uma de suas tias que, deixando o gato comer a moela preparada para o marido, foi espancada vertiginosamente por ele e enviada de volta para a casa da mãe para ser reeducada. Desorientada, põe-se a caminhar na calada da noite e depara-se com um leopardo. Este a devora. Moral: "Morreu na flor da idade por causa de uma imbecilidade. Morreu ela e ficou o gato" (N, p. 100). Finalmente, com a sogra, recebe a revelação de que os antepassados guiaram os seus passos "para a reunião da grande família, no grande dia". Assim, pela vOz de ritmo "doce, melodioso" e experiente da sogra, vê a sua condição de mulher traída e abandonada ser transformada na de "uma grande mulher" (Ibidem, p. 100).

Nesta condição maior, como a dos chefes dos tocadores de nyanga,. Rami passa a liderar, comandar e orientar as outras mulheres nos ritos, nos hábitos alimentares e na plena satisfação do marido. De inimigas e rivais, tornam-se unidas e irmãs. Rami as reune como numa "autêntica dança, um acto de coragem, um triunfo instantâneo no jogo de amor" (Ibidem, p. 111). E são os seus passos, unidos, que realizam uma dança niketche coletiva: as cinco mulheres se despem e carregam o homem para cama, desafiando o poder masculino e fazendo do marido o objeto comandado e subjugado pelo poder feminino:

Somos cinco contra um. Cinco fraquezas juntas se tornam força em demasia. Mulheres desamadas são mais mortíferas que as cobras pretas. (...) Era preciso mostrar ao Tony o que valem cinco mulheres juntas. Entramos no quarto e arrastamos o Tony, que resistia como um bode. Despimo-nos, em striptease. Ele olha para nós. Os seus joelhos ganham um tremor ligeiro" (Ibid., p. 143).

Como não perceber, na criação deste encontro, uma consonância direta com aquela prática da música moçambicana, apresentada, muitas vezes, em "contextos que dramatizam relações sociais, crenças, histórias, e acontecimentos comuns" (MARNEY, 1980, p. 34) ? Se, como nos faz crer John Marney, "a dança é um meio de expressão que pode ser relacionado com temas e propósitos de diversas ocasiões sociais" (Ibidem), então, Niketche constrói com propriedade e exatidão a dramatização de relações sociais e 
afetivas, não mais sob o comando dos passos masculinos, mas, agora, sob a voz e o ritmo femininos.

No entanto, é, talvez, na transição de um quase divórcio a uma falsa viuvez, quando da partida inesperada de Tony, que Rami aprende a mais dura das lições: dado o marido como "morto", não é apenas a poligamia, por influência do islamismo nortenho, ou o catolicismo arraigado presente na educação sulista que constituem a pressão maior sobre o sujeito feminino, é a própria tradição, cujas leis, segundo Paulina Chiziane, "são muito pesadas para uma mulher" (CHABAL, 1994, p. 298). E Rami, como mulher moçambicana, entende que "a cultura não é eterna" ( $N$, p. 311), mas o preço pago para mantê-la viva é alto demais, custa ao corpo e a alma da mulher moçambicana:

Eu grito, eu pergunto, como é que o Tony morreu e onde, quem o encontrou, quem o
matou, como o encontraram, como o identificaram. Aquelas mulheres respondiam-me:
porta-te como uma viúva digna. Não compreendia o que estava a acontecer, mas sabia que
uma viúva como deve ser não deve perceber nada, nem perguntar, nem sugerir nada, para
não ser chamada viúva fresca, viúva alegre. (...) Arrastaram-me para um canto, raparam-me
o cabelo à navalha e vestiram-me de preto. Acabava de perder poderes sobre o meu corpo
e sobre a minha própria casa. Arrependo-me: por que não assinei aquele maldito divórcio?
Tive nas mãos a oportunidade de libertar-me desta opressão e não a tomei. ( $N$, p. 198-199).

Sofrer com o corpo, sentir a sua própria feminilidade ferida e roubada e perder o controle sobre o corpo e a casa são os efeitos colaterais desta realização tradicional que atinge o seu ápice no rito da kutchinga, "da purificação sexual", quando o cunhado mais velho inaugura a "viúva na nova vida, oito dias depois da fatalidade" ( $N$, p. 212). Diferente da niketche, dança de "sensualidade perfeita, rainha de toda a sensualidade" (Ibidem, p. 160-161), a kutchinga é dança de posse e propriedade masculinas. Ainda assim, a mulher parece encontrar meios de subverter a marcação de um ritmo masculino, ao perguntar-se: "existira alguma mulher que, no acto da kutchinga, gemesse de prazer ?” (Ibidem, p. 213).

Diante da via crucis imposta a Rami, Tony se curva diante de uma "cultura assassina" (Ibidem, p. 229) e parece tomar consciência da verdadeira trajetória da mulher moçambicana, posto que "nem imaginava que as mulheres sofriam tanto. Sempre achara que a sociedade estava bem estruturada e que as tradições eram boas, mas só agora percebia a crueldade do sistema" (Ibidem, p. 229). Aquele que era o líder, o rei, vê o seu reino fragmentar-se diante do ritmo da niketche dançada por suas mulheres, posto que todas delas afirmam-se como "mulheres maduras" e "prontas para a vida" (Ibidem, 160) : "A Lu, a desejada, partiu para os braços de outro com véu e grinalda. A Ju, a enganada, está loucamente apaixonada por um velho português cheio de dinheiro. A Saly, a apetecida, enfeitiçou o padre italiano que até deixou a batina só por amor a ela. A Mauá, a amada, ama outro alguém." (Ibidem, p. 332). Diante da gravidez de Rami, a rainha, aquela que comandava a dança das mulheres, e da constatação do nome do pai: "O filho é do Levy" (Ibidem, p. 333), Tony vê o seu trono desabar. Muito diferente do tocador de timbila, que "só se inspira e transmigra até ao além quando a mulher se senta do seu lado, qual deusa, qual musa inspiradora" (Ibidem, p. 148), Tony é o executante destronado, abandonado, sozinho e trocado, e, como homem, sente na pele o ritmo da dança da vida imposto, muitas vezes de forma cruel, às mulheres africanas. Afinal de contas, não só no mundo da dança, mas também no da vida, quem não dança, dança.

E é no ritmo da niketche, que o romance de Paulina Chiziane parece deixar ecoar seus últimos sons. $\mathrm{Na}$ luta por seu espaço de liberdade, independência e complementaridade num mundo masculino, a lição deixada pela autora é mesmo aquela de que "as mulheres, de mãos dadas, podem melhorar o seu mundo", construindo um universo no ritmo da dança feminina e estabelecendo com esta uma contra-dança diante 
de um status quo masculino. Se, realmente, "quando a dança termina, podem ouvir-se entre os assistentes suspiros de quem desperta de um sonho bom" ( $N$, p. 161), então, nós, leitores ávidos, despertamos, esperando já uma outra dança, em que sejamos levados e embalados pelo doce ritmo desta contadora de histórias.

(Entregue para publicação em Março/2007,

Aprovado em Abril/2007)

\section{REFERÊNCIAS}

BRANDILY, Monique. Introducion aux musiques africaines. Paris: Cité de la musique / Actes Sud, 1997.

CHABAL, Patrick. Vozes Moçambicanas: Literatura e Nacionalidade. Lisboa: Veja, 1994.

CHIZIANE, Paulina. Niketche. São Paulo: Companhia das Letras, 2004.

."Ser escritora é uma ousadia!!!”. Entrevista ao Maderazindo. Revista Literária Moçambicana, [http:www.maderazinco.tropical.co.mz]. . Ventos do Apocalipse. Lisboa: Caminho, 1999.

GOMES, Júlio do Carmo. "Contadora de histórias". Entrevista ao Jornal de Letras, Artes e Idéias. Lisboa, 21 de março de 2001.

LUTERO, Martinho \& PEREIRA, Martins. "Nyanga: a dança das flautas". In: Música tradicional em Moçambique. Maputo: Ministério da Educação e Cultura, 1980, p. 60-71

MARNEY, John. "As tradições musicais em Moçambique". In: Música tradicional em Moçambique. Maputo: Ministério da Educação e Cultura, 1980, p. 10-16.

MATA, Inocência. "Paulina Chiziane: uma coletora de memórias imaginadas". In: Metamorfoses 1. Lisboa/Rio de Janeiro: Cosmos/Cátedra Jorge de Sena, 2000, p. 135-142.

MUSSÁ, Fátima Nordine. "Entre modernidade e tradição: a comunidade islâmica de Maputo". In: FRY, Peter (org). Moçambique: ensaios. Rio de Janeiro: Editora da UFRJ, 2001, p. 111-133. 